\title{
Use of Accelerometer for Walk-Run or Shot Analysis for Sport and Rehabilitation Purposes
}

\author{
Milan Stork, Petr Weissar, Kamil Kosturik \\ Department of Applied Electronics and \\ Telecommunications/RICE \\ University of West Bohemia \\ Plzen, Czech Republic \\ stork@kae.zcu.cz, weissar@kae.zcu.cz, \\ kosturik@kae.zcu.cz
}

\author{
Jaroslav Novak, Vaclav Zeman \\ Institute of Sports Medicine \\ Medical Faculty in Plzen \\ Charles University in Prague \\ Czech Republic \\ novakj@1fp.cuni.cz, \\ vaclav.zeman@1fp.cuni.cz
}

\begin{abstract}
Human movement analysis is a research field with clinical and biometrics application. It has been shown useful in the objective measurement of gait, balance, falls risk assessment and mobility monitoring. Running and/or walking are also integral activities to most athletic disciplines. From a technological point of view, biometric walk-run recognition can be categorized into three approaches: machine vision based, floor sensor based and wearable sensor based. In this paper the accelerometer-based walk-run and shot measuring system is described. The results can be used for medical and sport purposes and also for biometric identification. The electronic system and results of measurement walkrun under laboratory conditions have been presented.
\end{abstract}

Keywords - acceleration sensor; mobility monitoring; wireless connection; bluetooth

\section{INTRODUCTION}

A particular way or manner of moving on foot is the definition for gait. Every person has his or her own way of walking. Several human factors, such as age, injuries, gender, pace, lower extremities disorders and/or abnormalities etc. may change a person's walking style into a slight different walk, either permanent or temporary. Aged persons have a reduced range of hip motion at faster walking speeds and 5 degrees lower hip extension range compared to their young age [1]. It also appears from early medical studies that there are twenty-four different components to human gait, and that if all the measurements are considered, gait is unique $[2,3]$. This has made gait recognition an interesting topic to be used for identifying individuals by the manner in which they walk. Furthermore, running, jogging and walking are also very important for most sports. The analysis of biometric gait for medical purposes has been studied for a longer period of time [4 - 8]. It appeared to be useful also for identification and surveillance in forensic medicine, since the gait analysis provides more reliable and efficient means of identity verification. Fig. 1 illustrates the principle of

This work was supported by Department of Applied Electronics and Telecommunications, University of West Bohemia, Plzen, Czech Republic and by the Ministry of Education, Youth and Sports of the Czech Republic under the RICE - New Technologies and Concepts for Smart Industrial Systems, project No. LO1607 and by the Internal Grant Agency of University of West Bohemia in Pilsen, the project SGS-2015-002 and GA15-22712S. examination in laboratory. Patient (or runner) carries electronic system attached on the body. It consists from accelerometers and Bluetooth communication module. The subject can walk or run on treadmill ergometer, therefore speed and slope of the treadmill band can be exactly regulated. Measured values are sent wirelessly to personal computer. An important point to be noticed is that the running speed, slope angle, heart rate, carbon dioxide expenditure and oxygen consumption can be also measured during examination $[9,10]$. The electronic system can be used also for swing analysis in tennis, squash, badminton etc. [11 - 13]. The photo of running test on treadmill ergometer in laboratory is shown in Fig. 2.

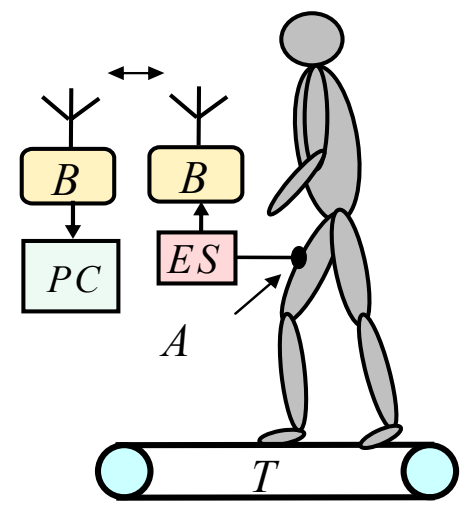

Figure 1. Block diagram of measuring system. $T$ - treadmill ergometrer, $A$ - accleration sensor (or sensors), $E S$ - electronic system, $B$ - bluetooth modules, $P C$ - personal computer.

\section{METHODS}

Apart from the machine vision and floor sensor based gait recognition, the wearable sensor for gait analysis is the most recent approach. This is based on attaching or wearing motion recording sensors on the body of the person in different places: on the waist, pockets, shoes etc. The sensors can have several purposes due to retrieving numerous types of data. Sensors of different types can for instance be accelerometers (to measure acceleration), gyro sensors (to measure rotation), force sensor (to measures the force when walking) etc, but most literature so far has put a great focus on accelerometer based gait recognition $[14,15]$. 
An accelerometer based gait recognition application can improve authentication in electronic devices. An example would be to implement the application in mobile phones. Due to the unobtrusive way of collecting data it can be applied for continuous-verification of the identity [16 - 21]. This means that for each step a user performs, the user's identity will be re-verified to ensure that it is not another person who has the mobile phone in hand, but the same user is authenticated. Researching at different methodologies to analyzing the features of gait is increasing and becomes a popular area of research, especially in gait biometrics [22 - 29]. Feature extraction from gait signals is a crucial for the efficient gait recognition. For a general gait analysis the digital signal processing is used. It is important to note that for sport purposes (fast running or shot analysis) the sampling frequency must be substantially higher then for slowly walking patients, therefore new electronic system was developed for this purposes.

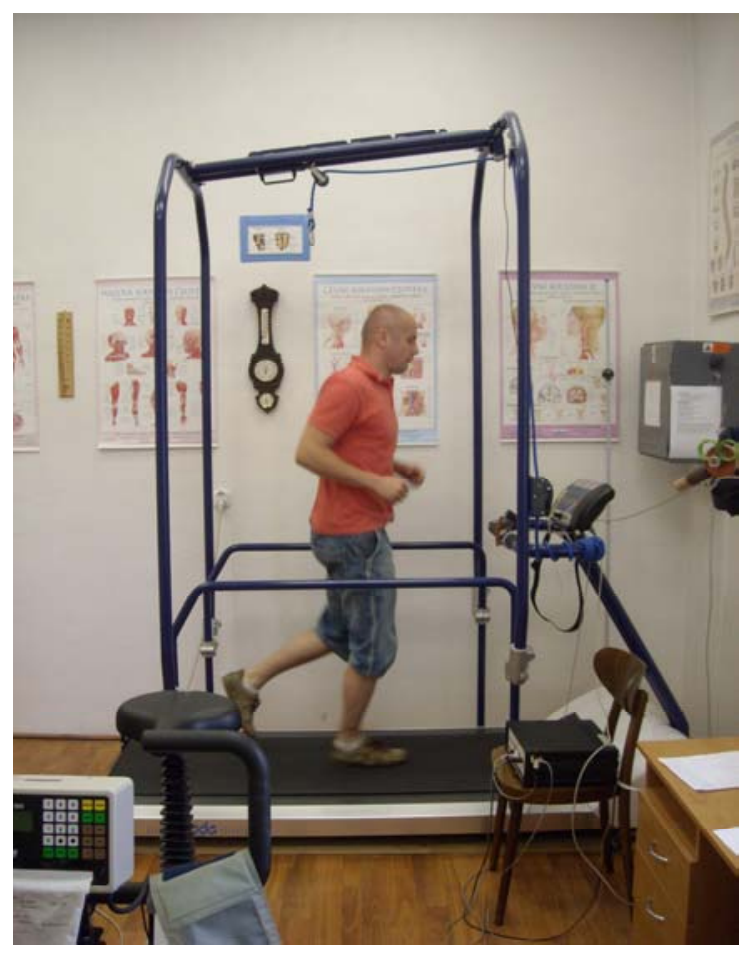

Figure 2. Measuring walk-run on treadmill ergometer in laboratory

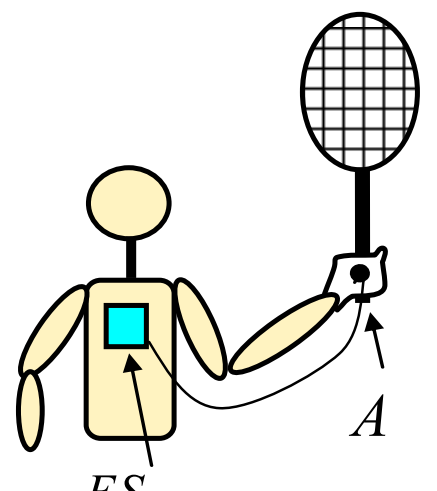

Figure 3. The shot acceleration measuring (e.g. for tennis swing). $A$ - accleration sensor, $E S$ - electronic system

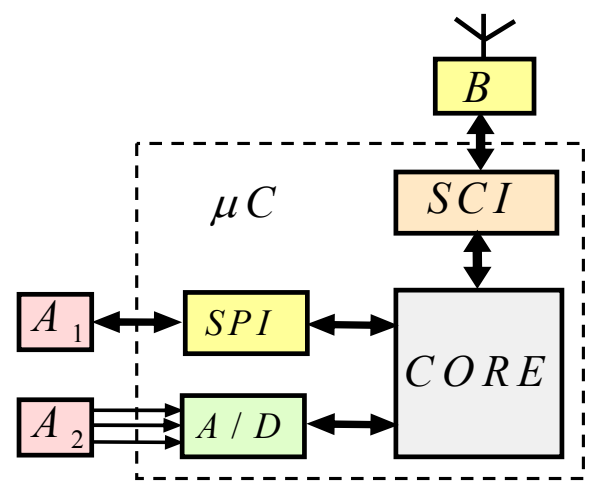

Figure 4. Block diagram of electronic system. $A_{1}$-acceleration sensor ADXL345, $A_{2}$ - acceleration sensor ADXL377, $B$ bluetooth module, A/D - analog/digital converter, $S P I$ - serial peripheral interface, $S C I$ - serial communication interface, $C O R E$ microcontroller core

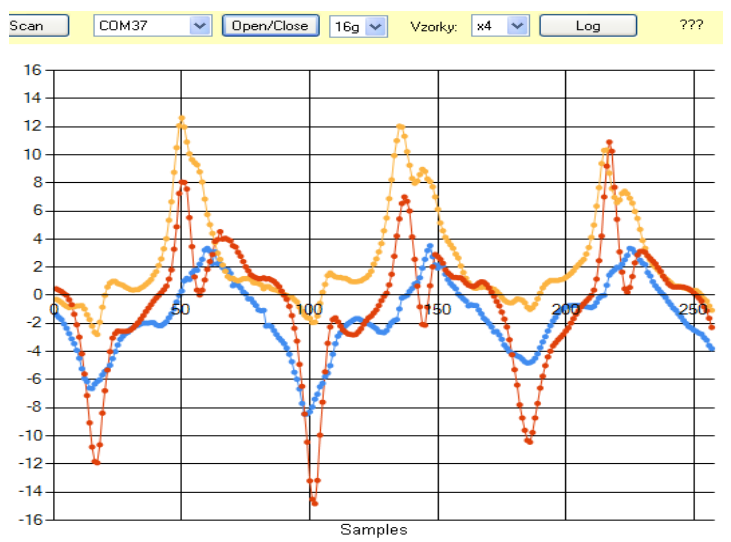

Figure 5. Example of real time acceleration measuring for $\pm 16 \mathrm{~g}$ range

Block diagram of electronic system is shown in Fig. 4. The 2 type's acceleration sensors were utilized. For walk-run purposes the ADXL345, 3-axis, $\pm 2 \mathrm{~g}$, $\pm 4 \mathrm{~g}, \pm 8 \mathrm{~g}, \pm 16 \mathrm{~g}$ digital accelerometrer was used [30]. Bandwidth can be set from $0.05 \mathrm{~Hz}$ to $1600 \mathrm{~Hz}$. (Therefore output data rate from $0.1 \mathrm{~Hz}$ to $3200 \mathrm{~Hz}$ ). $\mathrm{I}^{2} \mathrm{C}$ and SPI digital communications are available for ADXL345. Sampling frequency was $500 \mathrm{~Hz}$ for gait measurement and Bluetooth RN-42-DS was used for wireless connection to PC [31]. For fast, hard shot or swing measuring (e.g. tennis, squash, badminton, see Fig. 3) second type of accelerometer was used. The range can be developed by simple example. Suppose 60-g tennis ball approaches a racket at $v_{\mathrm{i}}=-16[\mathrm{~m} / \mathrm{s}]$. The ball is in contact with the racket for $\Delta t=0.004[\mathrm{~s}]$ and then rebounds at $v_{\mathrm{o}}=18[\mathrm{~m} / \mathrm{s}]$. The ball acceleration and average force exerted by rocket can be derived by

$$
\begin{array}{cc}
a=\left(v_{i}-v_{o}\right) / \Delta t= & {\left[\mathrm{m} . \mathrm{s}^{2}\right]} \\
(-16-18) / 0.004=-8500 & \\
F=m \cdot a=0.06 \cdot(-8500)=-510 \quad\left[\mathrm{~N}, \mathrm{~kg}, \mathrm{~m} . \mathrm{s}^{2}\right]
\end{array}
$$

The shot and acceleration is absorbed partly by hand but from previous example can be seen that wide range accelerometer must be used, therefore the ADXL377, 3-axis, $\pm 200 \mathrm{~g}$ accelerometer with analog outputs was used [32]. The ADXL377 has provisions for band-limiting the $\mathrm{X}_{\mathrm{OUT}}, \mathrm{Y}_{\mathrm{OUT}}$, and $\mathrm{Z}_{\mathrm{OUT}}$ pins. $\mathrm{A}$ 
capacitor must be added at each of these pins to implement low-pass filtering for antialiasing and noise reduction. A minimum capacitance of $1000 \mathrm{pF}$ for output pins is recommended (Bandwidth is $1 \mathrm{kHz}$ for $1000 \mathrm{pF}$ ). Sampling frequency was set to $1 \mathrm{kHz}$ (or 2 $\mathrm{kHz}$ ). The Freescale microcontroller MKL25Z128 was used for electronic system construction [33]. For real time measuring and data storage the new program was developed. Fig. 5 shows example of real time measurement (time evolution of $\mathrm{X}, \mathrm{Y}, \mathrm{Z}$ signal of accelerometer).

\section{RESUlTS OF MEASUREMENTS}

In this part the example of examination for fast walking-running attempts is presented. Long distance runner runs on treadmill $120 \mathrm{~min}$. Heart rate, pulmonary ventilation oxygen consumption parameters were continuously measured, see Fig. 6 . The measuring was two times interrupted for biochemical parameters measuring. Electronic system with accelerometer was placed in right leg and short periods of signal were periodically measured.
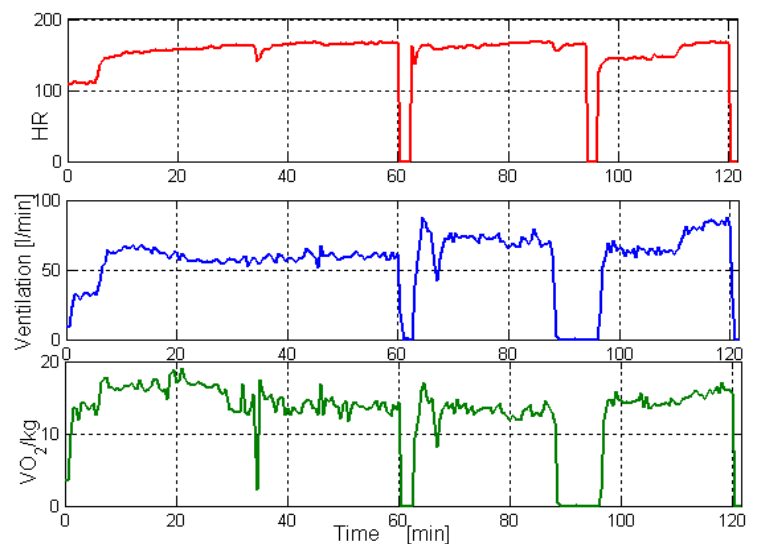

Figure 6. Long distance runner measurement example on treadmill ergometer - From top to bottom: Heart rate, pulmonary ventilation (in $1 / \mathrm{min}$ ), $\mathrm{VO}_{2} \cdot \mathrm{kg}^{-1}$ - (oxygen consumption per $\mathrm{kg}$ in $\mathrm{ml} / \mathrm{min}$ )

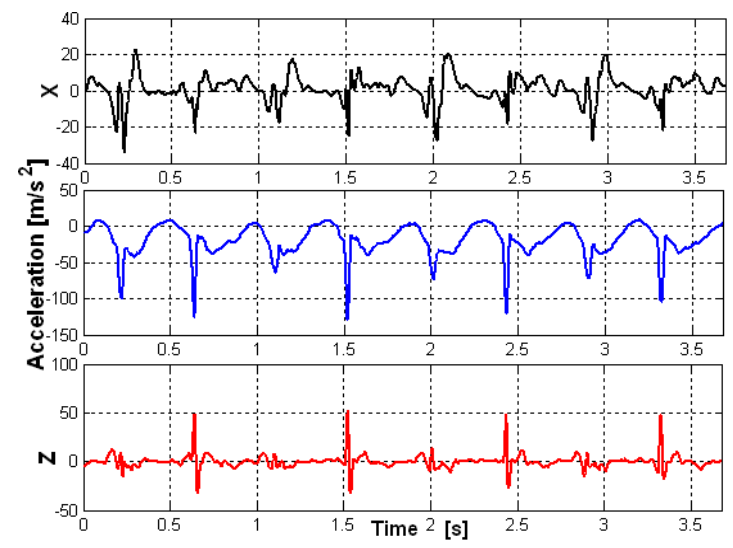

Figure 7. Long distance runner measurement example on treadmill ergometer. Time diagram of 3-axis accelerometer signals, $\mathrm{X}, \mathrm{Y}, \mathrm{Z}$ from top to bottom. Beginning of run

The time evolutions of signals from accelerometer are shown in Fig. 7. 3D phase projection is presented in Fig. 8 and frequency spectrum in Fig. 9. From frequency spectrum is possible find gait period which is confirmed by means of correlation diagram in Fig.
10. Signals in Fig. $7-10$ are taken on the beginning of run; frequency spectrum near on the end of examination is shown in Fig. 11.

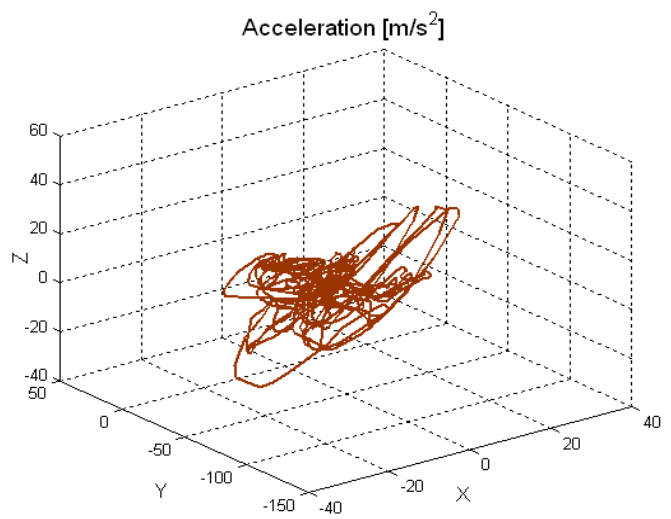

Figure 8. 3-D phase projection of accelerometer signals. Beginning of run

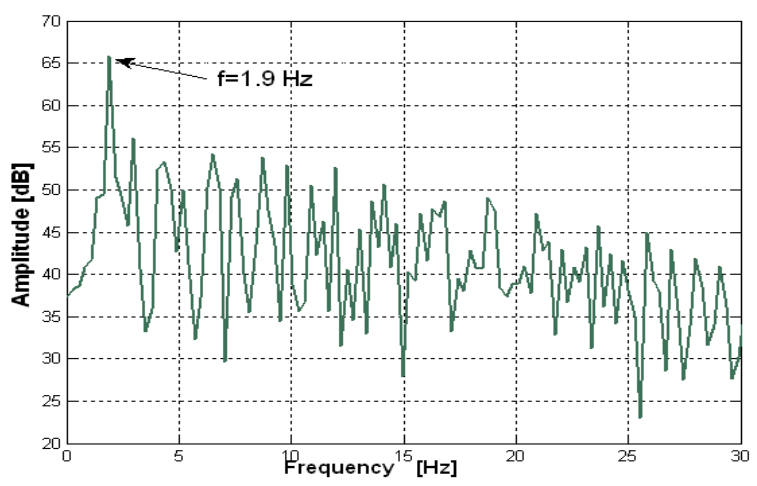

Figure 9. Frequency spectrum of signal Y. Peak value is $1.9 \mathrm{~Hz}$. Beginning of run

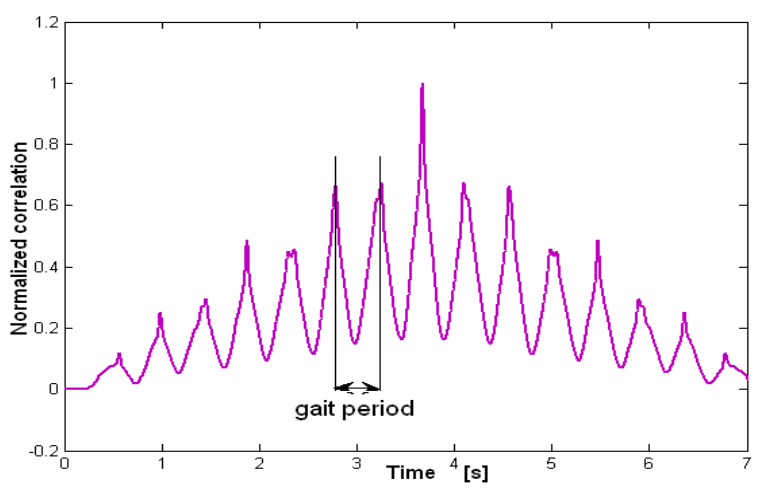

Figure 10. Normalized correlation of signal. Beginning of run

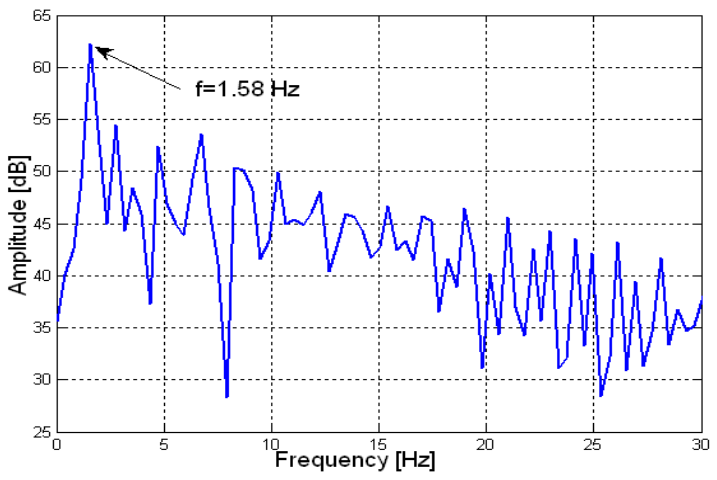

Figure 11. Frequency spectrum of signal on the end of examination. Peak value is $1.58 \mathrm{~Hz}$ 


\section{CONCLUSION}

In this paper the electronic system with two types of accelerometer sensors for run-walk or shot analysis for medical or sport purposes was described. Sampling frequency for such application must be much higher then sampling frequency usually used. Electronic system is wirelessly connected to personal computer which is used for real time measuring and also for data storing. Electronic system was designed for working in laboratory or outdoor but in range of Bluetooth transmitter-receiver. Example of measurements for long distance run was also presented but detailed evaluation of measuring was not described in this paper.

\section{REFERENCES}

[1] D. C. Kerrigan, "Kerrigan's unique research may unlock elder gait enigma," http://oscar.virginia. edu/researchnews/x11269. xml. [Online; accessed 27- September-2010]

[2] Chiraz BenAbdelkader, Ross Cutler, Harsh Nanda, and Larry S. Davis. Eigengait: Motion-based recognition of people using image self-similarity. In AVBPA, pp. 284-294, 2001.

[3] J. Perry, "History of the study of locomotion," http://www.univie.ac.at/cga/history/modern.html. [Online; accessed 27-September-2010].

[4] L. Wang, T. Tan, W. Hu, and H. Ning, "Automatic gait recognition based on statistical shape analysis," IEEE Transactions on Image Processing, 12(9):1120-1131, 2003.

[5] P.K. Larsen, E.B. Simonsen, and N. Lynnerup. Gait analysis in forensic medicine. J Forensic Sci, 2008.

[6] D. Gafurov, "Performance and Security Analysis of Gaitbased User Authentication," PhD thesis, Faculty of Mathematics and Natural Sciences, University of Oslo, 2008.

[7] S. Sprager and D. Zazula, "Gait identification using cumulants of accelerometer data," In SENSIG'09/VIS'09/MATERIALS'09: Proceedings of the 2nd WSEAS International Conference on Sensors, and Signals and Visualization, Imaging and Simulation and Materials Science, pages 94-99, Wisconsin, USA, 2009. WSEAS.

[8] C. Y. Lee and Ju-Jang Lee, "Estimation of walking behavior using accelerometers in gait rehabilitation," International Journal of Human-friendly Welfare Robotic Systems, 2004, pp. 3:32-36.

[9] J. A. Fairley, E. Sejdic, T. Chau, "The effect of treadmill walking on the stride interval dynamics of children," Human Movement Science 29, 2010, pp. 987-998

[10] D. Damiano \& S. DeJong, "A systematic review of the effectiveness of treadmill training and body weight support in pediatric rehabilitation," Journal of Neurologic Physical Therapy, 33, 2009, pp. 27-44.

[11] U. Kuenzler, W. Englert, "Device and method for measuring a shot force exerted on a movable game device," Patent US7891666, 2011.

[12] C. White, "Projectile Dynamics in Sport," (1st ed.), Milton park, Oxon: Routlegde, 2011.

[13] B. Auvinet, E. Gloria, G. Renault, E. Barrey, "Runner's stride analysis: comparison of kinematic and kinetic analyses under field conditions," Science\& Sports 17,2002, pp. 92-94

[14] L. Rong, Z. Jianzhong, L. Ming, and H. Xiang, "A wearable acceleration sensor system for gait recognition," In Industrial Electronics and Applications, ICIEA 2007, 2007, pp. 26542659
[15] L. Rong, Z. Jianzhong, L. Ming, and H. Xiang, "Identification of individual walking patterns using gait acceleration," In 1st International Conference in Bioinformatics and Biomedical Engineering, 2005, pp. 543-546.

[16] M. Hynes, H. Wang, and L. Kilmartin, "Off-the-shelf mobile handset environments for deploying accelerometer based gait and activity analysis algorithms," Conf Proc IEEE Eng Med Biol Soc, 2009, pp. 1:5187-90.

[17] T. Weijun, T. Liu, R. Zheng and H. Feng, "Gait Analysis Using Wearable Sensors," Sensors 2012, 12, 2255-2283; doi:10.3390/s120202255

[18] S. Bamberg, A. Benbasat, D. Scarborough, D. Krebs, J. Paradiso, "Gait analysis using a shoe-integrated wireless sensor system,”. IEEE Trans. Inf. Technol. Biomed. 2008, 12, pp. 413-423.

[19] A. Salarian, H. Russmann, F. Vingerhoets, P. Burkhard, K. Aminian, "Ambulatory monitoring of physical activities in patients with parkinsonapos's disease,". IEEE Trans. Biomed. Eng. 2007, 54, pp. 2296-2299.

[20] S. Moore, H. MacDougall, W. Ondo, "Ambulatory monitoring of freezing of gait in Parkinson's disease,". J. Neurosci. Methods 2008, 167, pp. 340-348.

[21] K. Turcot, R. Aissaoui, K Boivin, M. Pelletier, N. Hagemeister, J. de Guise, "New accelerometric method to discriminate between asymptomatic subjects and patients with medial knee osteoarthritis during 3-D gait," IEEE Trans. Biomed. Eng. 2008, 55, pp. 1415-1422.

[22] Y. Wahab, N. Bakar, "Gait analysis measurement for sport application based on ultrasonic system," In Proceeding of the IEEE 15th International Symposium on Consumer Electronics, Singapore, 14-17 June 2011.

[23] T. Liu, Y. Inoue, K. Shibata, "Development of a wearable sensor system for quantitative gait analysis,". Measurement 2009, 42, pp. 978-988.

[24] A. Sant'Anna and N. Wickström, "DEveloping a Motion Language: Gait Analysis from Accelerometer Sensor Systems," 3rd International Conference on Pervasive Computing Technologies for Healthcare, London, 1-3 April, 2009, pp. 1-8.

[25] B. Sun, Y. Wang and J. Banda, "Gait Characteristic Analysis and Identification Based on the iPhone's Accelerometer and Gyrometer," Sensors 2014, 14, 17037-17054; doi:10.3390/s140917037

[26] A. Herran, B. Garcia-Zapirain, A. Mendez-Zorrilla, "Gait Analysis Methods: An Overview of Wearable and NonWearable Systems," Highlighting Clinical Applications. Sensors 2014, 14, pp. 3362-3394.

[27] Moore et al.,. "Autonomous identification of freezing of gait in Parkinson's disease from lower-body segmental accelerometry," Journal of NeuroEngineering and Rehabilitation 2013, pp. 10:19

[28] D. Delignières, \& K. Torre, "Fractal dynamics of human gait,": A reassessment of the 1996 data of Hausdorff et al. Journal of Applied Physiology, 2009, 106, 1272-1279.

[29] J. Hausdorff, P. Purdon, C. Peng, Z. Ladin, J. Wei, \& A. Goldberger, "Fractal dynamics of human gait: Stability of long-range correlations in stride interval fluctuations,". Journal of Applied Physiology, 1996, 80, 1448-1457.

[30] ADXL345 3-Axis, $\pm 2 \mathrm{~g} / \pm 4 \mathrm{~g} / \pm 8 \mathrm{~g} / \pm 16$ g Digital Accelerometer, Analog Devices

[31] RN42/RN42N Class 2 Bluetooth Module, http://www.microchip.com/ downloads/en /DeviceDoc/rn-42ds-v2.32r.pdf

[32] ADXL377 Small, Low Power, 3-Axis $\pm 200 \mathrm{~g}$ Accelerometer, Analog Devices

[33] KL25 Sub-Family Reference Manual Document Number: KL25P80M48SF0RM Rev. 3, Freescale, September 2012 x 